\section{Rare earth elements in wastewater - new members in the anomalous suite}

\section{ŽELJKA FIKET AND NIKOLINA UDIKOVIĆ KOLIĆ}

Ruđer Bošković Institute

Presenting Author: zeljka.fiket@irb.hr

Rare earth elements (REE) are omnipresent and their natural levels are usually conditioned by geological and pedological background. However, their growing use for medicinal purposes over the last few decades (in cancer therapy and imaging; [1]) has resulted in their increasing presence in natural water systems, especially in areas of intense human activity [2-5].

Often termed as "new pollutants", this group of elements displays enrichment in natural water systems, exceeding in some cases natural levels by three orders of magnitude. Consequently, positive anomalies of certain elements, e.g. $\mathrm{La}$ and $\mathrm{Gd}$, have been recorded worldwide; in Europe, the USA, Australia, Taiwan, and Japan, mainly in densely populated areas with highly developed health systems [2-5].

In this study, the distribution of REE in wastewater from seven major Croatian cities and their fractionation compared to natural water systems was investigated.

Obtained REE distribution in wastewater samples indicates not only the marked REE wastewater load comparable to other large cities in the region but also the impossibility of their successful elimination during wastewater treatment. Furthermore, the positive anomalies in wastewater samples were observed for several elements of the group ( $\mathrm{Gd}$, Ho and $\mathrm{Yb}$; Figure 1), suggesting their enrichment by up to four orders of magnitude compared to natural water systems.

Obtained data emphasize the necessity to more closely monitor REE levels in aquatic systems and to investigate their possible bioaccumulation and/or toxicological effects.

\section{References:}

[1] Teo, Termini \& Gray (2016), Journal of medicinal chemistry 59(13), 6012-6024.

[2] Brünjes \& Hofmann (2020), Water Research 182, 115966.

[3] Lawrence (2010), Marine Pollution Bulletin 60(7), 11131116 .

[4] Kulaksız \& Bau (2011), Environment International 37(5), 973-979.

[5] Klaver, Verheu, Bakker et al. (2014), Applied Geochemistry 47(0),186-197.

\section{Acknowledgment:}

This work has been supported by Croatian Science Foundation under the projects IP-2019-04-9354 (FORtIS) and IP-2019-045539 (WasteCare).

Figure 1. Gadolinium $\left(\mathrm{Gd} / \mathrm{Gd}^{*}=\mathrm{Gd}_{\mathrm{NASC}} /\left[\left(0.33 \mathrm{xSm} \mathrm{NASC}_{\mathrm{NC}}\right)+\right.\right.$ $\left.\left.\left(0.67 \times \mathrm{xb}_{\mathrm{NASC}}\right)\right]\right) ; \quad$ ytterbium $\quad\left(\mathrm{Yb} / \mathrm{Yb}^{*}=\right.$ $\left.\mathrm{Yb}_{\mathrm{NASC}} /\left(\mathrm{Tm}_{\mathrm{NASC}} \times \mathrm{Lu}_{\mathrm{NASC}}\right)^{0.5}\right)$ and holmium $\left(\mathrm{Ho} / \mathrm{Ho}^{*}=\right.$ $\left.\mathrm{Ho}_{\mathrm{NASC}} /\left(\mathrm{Dy}_{\mathrm{NASC}} \times \mathrm{Er}_{\mathrm{NASC}}\right)^{0.5}\right)$ anomalies in studied samples.

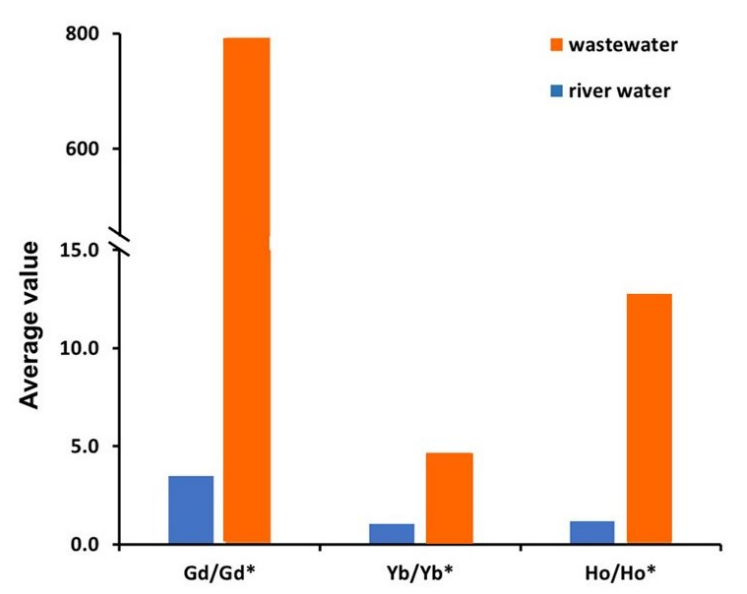

